\title{
Digital Economy Is A Guarantee Of Government And Society Development
}

\author{
Farkhod Mulaydinov, Head of the Business department, Kokand University Uzbekistan
}

\begin{abstract}
The article analyzes the experience and achievements of developed countries in the field of the digital economy, factors and problems of its formation and development in the country, the contribution of the industry to added value and employment in the economy, the author's views on the formation and development of the digital economy in Uzbekistan.
\end{abstract}

Keywords: digital economy, digital technologies, Internet technologies, community development, social networks, netizens, blockchain. Received: 06.12.2020 Accepted: 10.01 .2021 Published: 07.02.2021

\section{Introduction}

The Decree of the President of the Republic of Uzbekistan Shavkat Mirziyoyev dated February 19, 2018 "On measures to further improve the field of information technology and communications" was adopted and important tasks for the accelerated development of the industry were identified. In the current year "Development of Science, Enlightenment and Digital Economy" within the State Program it is planned to spend about 30 trillion soums for the rapid development of the economy.

\section{Review of research on the topic}

In recent years, there has been a great deal of scholarly work and scholarly literature explaining concepts such as the transition to an information society, the digital economy, and the knowledge economy. First of all, it is necessary to note the translation work devoted to the creation and effective use of knowledge. In 1995, American programmer Nicholas Negroponte coined the term "digital economy." Today, the term is used by politicians, economists, journalists, and entrepreneurs around the world. In 2016, the World Bank published the first report on the state of the global digital economy ("Digital Dividends") [1,2].

One of the brightest examples of the development of digital platforms is a Chinese company with an e-commerce system Alibaba. Experience in its use shows that in the process of data collection, very competitive advantages are created for expansion into different sectors of the economy. "Alibaba" is not just a digital platform, but a platform ecosystem. The digital economy will significantly increase people's living standards, which is its main benefit.

The digital economy is a major ally of corruption and "the black economy". Because numbers seal everything, store it in memory, and provide information quickly when needed. In such circumstances, it is impossible not to hide any information, to make secret transactions, not to give full information about this or that activity, the computer will show it all. The abundance and structure of the data prevent lies and deception because it is impossible to deceive the system. As a result, it is impossible to launder "dirty money", steal funds, spend them inefficiently and aimlessly, exaggerate or hide. This will increase the flow of legal funds to the economy, taxes will be paid on time and correctly, budget allocations will be transparent, funds allocated to the social sphere will not be stolen, money allocated for schools, hospitals, roads will reach in full, and so on.

\section{Research methodology}

The research process used methods of cognitive theory such as induction and deduction, logical approach, time and space, comparative analysis. The research has generalized conclusions and recommendations on the state of the use of digital technologies in the world and our country, the achievements in this area, and the issues that need to be addressed. The methods of analysis and synthesis, economic and statistical analysis, graphical comparison were used in the study of the activities of the countries.

\section{Research results}

It should be noted that the digital economy is a very complex system, shaped by man, a comprehensive system that manages, defines, organizes, plans, and all this is aimed at ensuring sustainable economic growth, improving human life, living standards. 
Research shows that ICT should be widely used in the creation and use of knowledge, as it serves both producers and consumers of knowledge. The first group includes information and communication technologies, science and research and development (SRD), education, high-tech production, nano and biotechnology (specialists, engineers, researchers, programmers, designers, professors, etc.) can be added.

The share of the digital sector in innovation development in the world is growing. It is especially important to study China's experience in this field. China's three digital giants Baidu, Alibaba, Tencent, and Xiaomi (referred to briefly in the literature as BATX) are becoming global leaders in digital innovation. They are world leaders in the export of digital goods and services. In the 2017 Declaration of the G - 20 Economic Ministers, the International Monetary Fund and the OECD agreed on the need to study the impact of digitalization on GDP.

Let's take a look at the statistics of Digital Around the World in 2020 (Digital Coverage Around the World in 2020) by We Are Social and Hootsuite companies on Internet users and services in the world. As of January 2020, the world's population reached 7.75 billion. Of these, 5.19 billion. unique mobile device users or $67 \%$ of the total world population, the number of Internet users is 4.54 billion. or $59 \%$ of the total world population, Active social media users are 3.80 billion or $49 \%$ of the total world population.

The total population growth over the year increased by $1.1 \%$ (82 million), users of unique mobile devices by $2.4 \%$ (124 million), Internet users by 7\% (298 million), and active media users by $9.2 \%$ (321 million).

Share of Internet users:

The highest rate is in $95 \%$ of Northern European countries, the lowest rate is in $22 \%$ of Central African countries, and $54 \%$ of the population in Central Asian countries use the Internet.

Those who are not connected to the Internet (million people):

The region with the largest number of people without access to the Internet in South Asia with 1.012 billion people, the region with the least number of people without access in Northern Europe with 5 million people, and 34 million people in Central Asia are not connected to the Internet [7].

Below are the names of the Social Network with the most users (million people as of April 2020 [8]).

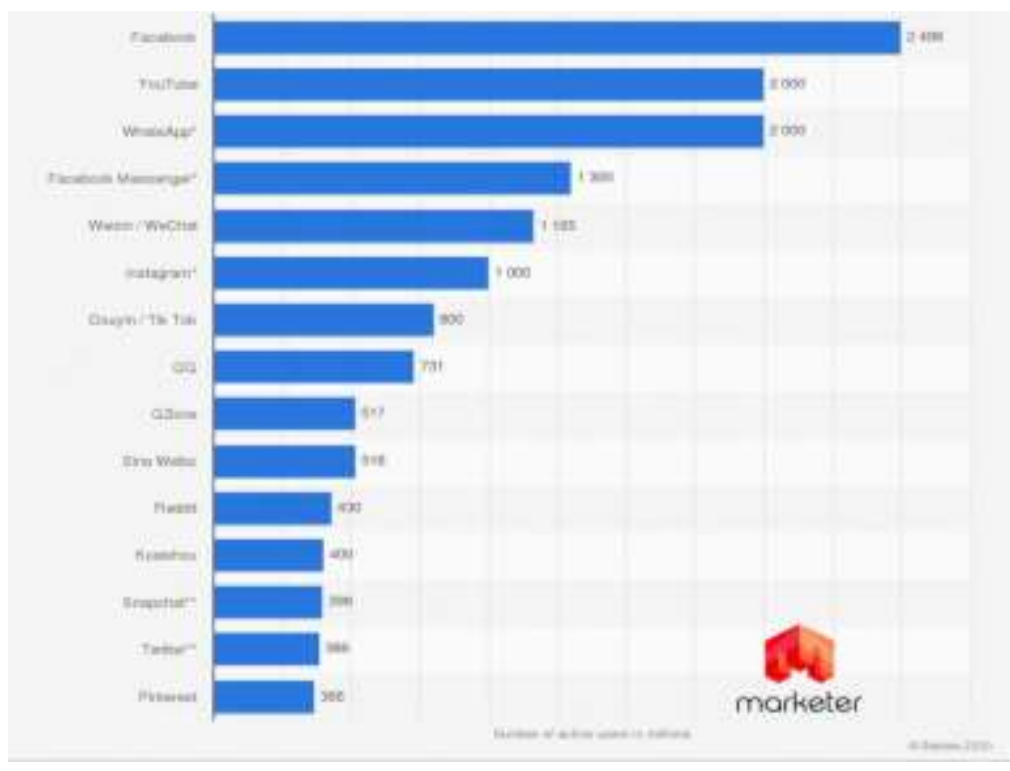

The speed of the Internet has been increasing rapidly in recent years, as can be seen in the statistics provided by the Digital Economy Report - UNCTAD.

Internet traffic $(\mathrm{GB} / \mathrm{s})[9]$ 


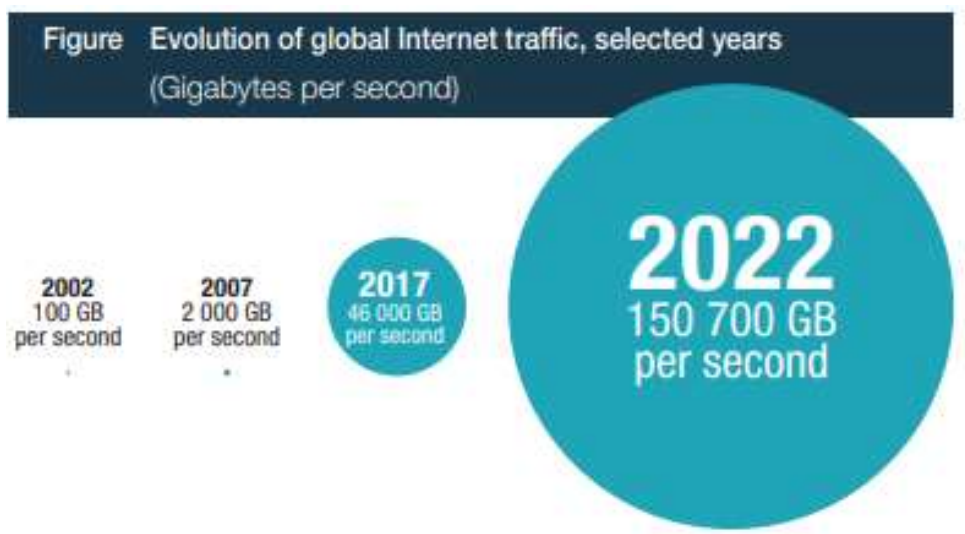

From the picture above, we can say that by 2022 , the speed of the Internet is expected to increase 1,500 times in 20 years.

Experts from the Shanghai Academy of Social Sciences have released the Global Digital Economy Competitiveness Development Report (2019) for the countries with the most competitive digital economies in the world. According to him, the leading countries in the field of the digital economy are: USA, Singapore, China, the UK, Finland, South Korea, Japan, the Netherlands, Australia, and Germany.

PwC has announced the Top 10 companies with the highest capitalization by analyzing the top 100 companies in the world as of March 31, 2020 [6].

\begin{tabular}{|c|c|c|c|}
\hline $\begin{array}{ll}\text { Name } & \text { of } \\
\text { organization }\end{array}$ & Capitalization & Country & The field \\
\hline Apple inc. & $\$ 2,0$ trillion & The U.S. & $\begin{array}{l}\text { Electronics, } \\
\text { information } \\
\text { technology }\end{array}$ \\
\hline Saudi Aramco & $\$ 1,9$ trillion & Saudi Arabia & Oil and gas \\
\hline Microsoft & $\$ 1,3$ trillion & The U.S. & Software \\
\hline $\begin{array}{l}\text { Alphabet } \\
\text { Inc.(Google) }\end{array}$ & $\$ 1,0$ trillion & U.S. & Internet \\
\hline Amazon Inc. & $\$ 924.5$ billion & The U.S. & Retail \\
\hline Facebook & $\$ 633.5$ billion & The U.S. & Internet \\
\hline Alibaba Group & $\$ 610.1$ billion & China & Retail \\
\hline $\begin{array}{l}\text { Berkshire } \\
\text { Hathaway Inc. }\end{array}$ & $\$ 562.4$ billion & The U.S. & $\begin{array}{l}\text { Insurance, finance, } \\
\text { railways, etc. }\end{array}$ \\
\hline Tencent & $\$ 492.9$ billion & China & Internet \\
\hline Visa Inc. & $\$ 441.6$ billion & The U.S. & Financial services \\
\hline
\end{tabular}


As you can see in this table, 7 out of 10 of the world's top companies are in the US. This is proof that the above is consistent with the results of the Global Digital Economy Competitiveness Development Report (2019). Also, 8 of the Top 10 companies listed in this table (Apple inc., Microsoft, Alphabet Inc. (Google), Amazon Inc., Facebook, Alibaba Group, Tencent, and Visa Inc.) operate in the digital economy or have significantly higher affiliations. It is not difficult to understand that these are companies that are. If you calculate the total capitalization of these companies is about 7.4 trillion. \$. In terms of GDP, the world lags behind the United States ( $\$ 23.5$ trillion), China ( $\$ 21.4$ trillion), and India ( $\$ 9.6$ trillion). This means that the development of the digital economy is as necessary for today's developing countries as water and air.

The number of laws regulating ICT in the country is currently about 30 . The main ones are the laws of the Republic of Uzbekistan "On Informatization", "On Electronic Digital Signature", "On Electronic Commerce", "On Electronic Document Management" and others.

In the formation of the national information system, the mass introduction and use of modern information technologies, computers, and telecommunications in all sectors of the economy and society, to better meet the growing information needs of citizens, access to the global information community, and access to global information resources. The teaching of the subject "Information Technology and Systems" is of great importance in the expansion.

Electronic information, monitoring, and management systems cover all modern production and large service sectors, including electricity, water, and gas supply. E-governance is provided by all types of transport communications, including national and interstate highways. Electronic control will be introduced in the irrigated farming system.

The number of Internet service operators and providers is constantly growing due to the growing competitive environment in the countries.

Table - 1

\begin{tabular}{|c|c|c|c|c|}
\hline \multicolumn{5}{|c|}{ Indicators of formation and development of the digital economy (2019) } \\
\hline Indicators & 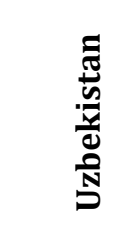 & $\tilde{U}$ & 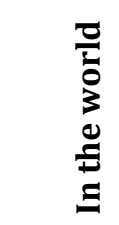 & 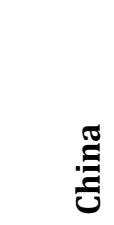 \\
\hline Fixed telephone connection (per 100 people) & 12,7 & 13,85 & 13,36 & 28,5 \\
\hline Mobile communication (per 100 people) & 71,5 & 104,27 & 97,65 & 115,5 \\
\hline Active mobile network connection (per 100 people) & 62,4 & 63,73 & 61,89 & 93,5 \\
\hline Mobile network price $1 \mathrm{G}(\$)$ & 1,34 & 1,23 & 3,75 & 0,61 \\
\hline $\begin{array}{l}\text { The cost of wired Internet is the average monthly cost of } \\
\text { Internet packages }(\$)\end{array}$ & 11,44 & 32,68 & 83,32 & 31,41 \\
\hline Percentage of Internet users, $\%$ & 55,2 & 58,65 & 54,13 & 54,3 \\
\hline Average wired internet network speed per user (Mbit/s) & 30,14 & 40,93 & 81,46 & 136,54 \\
\hline Average mobile internet network speed per user (Mbit/s) & 11,99 & 23,2 & 34,51 & 105,11 \\
\hline
\end{tabular}

Source: [12-16]

The table shows that due to the great attention paid to the development of information and communication technologies and the Internet in the country, the industry is developing rapidly. However, the speed of the Internet, the cost of mobile and mobile networks, the availability of mobile communication lags in the world, and the Commonwealth of Independent States. Although the majority of providers and operators are concentrated in Tashkent, their number is growing in the country, especially in Samarkand and Bukhara. This indicates that competition is intensifying in this segment of the market. Along with the increase in the capacity of channels and the number of operators and providers, the number of subscribers to the system of communication and broadband access to the Internet is growing rapidly.

The number of public Internet access points in the country is growing (PIA). This is facilitated by the simplification of the licensing process of these outlets. The use of Wi-Fi technology to connect to the Internet is also expanding. According to the results of the experiment, the State Radio Frequencies Commission allocated frequency bands to each operator to develop broadband wireless networks using 
WiMAX technology in the country. This allows you to create wireless networks that cover large areas.WiMax 2 technology operates at $802.16 \mathrm{~m}$ standard and up to $1 \mathrm{Gbit} / \mathrm{s}$ on the WMAN network and up to $100 \mathrm{Mbit} / \mathrm{s}$ on the Mobile WMAN network. Radius coverage is expected to be $120-150 \mathrm{~km}$ (in development). At the same time, frequencies have been allocated for the development of wireless networks based on Wi-Fi technology. They are designed to create wireless local (intra-office) networks and to create high-speed wireless connections to the Internet with a data transfer rate of $54 \mathrm{Mbit} / \mathrm{s}$.

The area of Internet access using Wi-Fi technology is being expanded. As a result, the number of Wi-Fi hotspots will increase.

\section{Conclusion}

Today, there are about 8 billion people in the world, and about $60 \%$ of them are connected to the Internet. This means a market with more than 5 billion participants. However, in developed and developing countries, there is still a large gap (digital gap) in the level of use of information technology by rural and urban populations. Among the problems in the development of the digital economy in our country is the level of literacy of the population in this area, Internet speed, Internet access in remote villages, infrastructure, and lack of skills and specialists.

It should be noted that in a country where the Internet and its services, which are elements of the digital economy, are well established and the population uses it effectively, there are many giant companies in those countries, which in turn increases the living standards of the population. In the Top Companies chart above, we can understand that it is mainly the digital economy and the companies associated with it. Also, these giant companies are mainly U.S. and Chinese companies.

The rapid development of information and communication technologies (ICT) is not only affecting enterprises and small businesses in our country but also becoming one of the most important factors that will radically change their business and office activities. The experience of developed countries shows that the free flow of information has a positive impact on the rapid transition to a market economy and the improvement of social life. Based on the rapid penetration of the Internet and ICT into our lives, it can be said that such innovations and innovations, businesses that have not mastered the new set of knowledge in time, even countries will lose their market share in the future and compete due to globalization. their behavior is natural[3-4].

In conclusion, the digital economy is an integral part of developed countries, and the attention paid to its development pays off many times over. To be a developed country, of course, it is more important than ever to focus on the digital economy today, because the shortest way to growth is the digital economy.

\section{References}

1. How big is China's digital economy? Bruegel, Working Paper, Issue 04, 17 May 2018

2. China's Digital Economy a Leading Global Force. MGI Discussion Paper, August 2017

htpp://www.itu.int/eng/ITU-D/

3. F.Mulaydinov, R.Tokhirov, D.Mamayusupova. Trends In Solving Problems In The Development Of An Innovative Economy. Journal of Advanced Research in Dynamical and Control Systems. Volume 12, Issue 6, 2020. DOI: 10.5373/JARDCS/V12I6/S20201160. Pages: 1205-1209.

4. F.Mulaydinov, A.Kadirova, G.Melibaeva, O.Akhmadjonov. Advantages Of The Transition To A Digital Economy In The Innovative Development Of Uzbekistan. Journal of Advanced Research in Dynamical and Control Systems. Volume 12, Issue 6, 2020. DOI: 10.5373/JARDCS/V12I6/S20201164. Pages: Pages: 1226-1232.

5. Top 10 most competitive digital economies in the world https://www.vesti.ru/finance/article/1271238

6. Top 10 companies by market capitalization in $2020 \mathrm{https} / /$ www.vesti.ru/finance/article/2419923.

7. Digital Around the World in 2020 - https://hootsuite.com/resources/digital-2020

8. Social networks, the most popular in Ukraine and the countries of the world 2020 https://marketer.ua/the-most-popular-social-networks-in-the-world/

9.Digital Economy Report - UNCTAD-https://unctad.org/en/PublicationsLibrary/der2019_en.pdf

10. FarkhodMulaydinov (2020). Econometric Modelling of the Innovation Process in Uzbekistan, International Journal of Psychosocial Rehabilitation, Vol. 24, Issue 02, 2020, Pages 359-367, ISSN: 14757192, https://doi.org/10.37200/IJPR/V24I2/PR200343.

11. What do you need to know about the digital economy? https://teletype.in/@huquqiy_axborot/BJwzhaFbU

12. Global Speeds July 2020https://www.speedtest.net/global-index 
13. United NationsE-government survey 2020. The digital government in the decade of action for sustainable development. UNITED NATIONS, New York, 2020. publicadministration.un.org

14. What Does 1GB of Mobile Data Cost in Every Country?https://www.visualcapitalist.com/cost-ofmobile-data-worldwide/

15. Worldwide mobile data pricing: The cost of $1 \mathrm{~GB}$ of mobile data in 228 countries. https://www.cable.co.uk/mobiles/worldwide-data-pricing/

16. The cost of fixed-line broadband in 206 countries. https://www.cable.co.uk/broadband/pricing/worldwide-comparison/ 